\section{Use of dichloro-difluoromethane aerosols in preparing frozen sections}

\author{
M. F. CASLING AND C. R. TRIBE From \\ the Pathology Laboratory, Wycombe General \\ Hospital, High Wycombe, Bucks
}

The advent of the cryostat had significantly advanced frozen section techniques. It is now the standard method for producing tissue sections in histochemistry and immunofluorescence studies and has improved the preparation of frozen sections for rapid histological diagnosis. The best method for the initial freezing of the tissues before section is, however, still controversial. This difficulty of quick freezing also arises with the traditional frozen section apparatus in small hospitals without histology laboratories, and in places where cryostats are not available.

To satisfy a local demand for a highly portable frozen section apparatus several methods to give freezing facilities with a minimum of bulk and weight were tried. Ethyl chloride was discarded as too slow and inefficient, with the added hazard of using toxic inflammable vapour near operating theatres. Carbon dioxide cylinders of $2 \mathrm{lb}$ capacity were used for some years but the weight of the cylinders (12 lb each) and the need to carry two cylinders with the apparatus made us look for a less bulky method. Thermomodule units working on the Peltier principle were tried with some success but, although they permit easier sectioning, the transformer required with these units weighed $14 \mathrm{lb}$ and the cold running water needed to cool the freezing head was not always conveniently available.

Eighteen months ago dichloro-difluoromethane was tried as a freezing agent, and for the last 12 months it has been used routinely, both with the cryostat in the main histology laboratory, and with the portable apparatus described here.

Dichloro-difluoromethane (Freon 12) is a gas used in the manufacture of refrigerators and is available in $12 \mathrm{oz}$ aerosol cans under the trade name of Arctic Spray ${ }^{1}$ for use in the plumbing and electronic industries. It is noninflammable, colourless, has little or no toxic effects except at very high temperatures, and is therefore completely safe in routine use (Thomas, 1965).

Each can provides approximately six minutes of continuous spray through a narrow polythene tube which can be accurately directed onto small pieces of tissue. In tissue up to $3 \mathrm{~mm}$ thick, temperatures of approximately minus $50^{\circ} \mathrm{C}$ can be achieved in five to 10 seconds. This rate and degree of freezing is comparable with carbon dioxide. There are no special storage containers such as

'Available from Electronic Chemicals Ltd., 30, Notting Hill Gate, London W.11.

Received for publication 11 April 1968. are required for liquid oxygen, liquid nitrogen, or soliơ carbon dioxide, and the cans can be kept at room? temperature with an indefinite shelf life. Dichloro difluoromethane is also economical and compares? favourably in price with other freezing agents.

The technique for using this freezing agent is describect with cryostats and with a specially designed portablen frozen section apparatus.

TECHNIQUE FOR USING DICHLORO-DIFLUOROMETHANE AS Â FREEZING AGENT WITH CRYOSTATS

The fresh tissue to be frozen is placed upon a previously $\overrightarrow{\vec{t}}$ wetted chuck face. Sections from tissue up to $5 \mathrm{~mm}$ thiclo have been prepared without difficulty. A few short burst from the aerosol are directed at the chuck below the fact to attach the tissue to the chuck. Short bursts (approxi $N$ mately one second each) are directed at the tissue itself untif freezing is complete (average number of bursts for routines frozen section on breast tissue is around seven). The chuck can now be placed in the cryostat and the tissue sectioned in the routine manner.

TECHNIQUE FOR USING DICHLORO-DIFLUOROMETHANE WITH A PORTABLE FROZEN SECTION APPARATUS

The frozen section apparatus is packed ready for use in

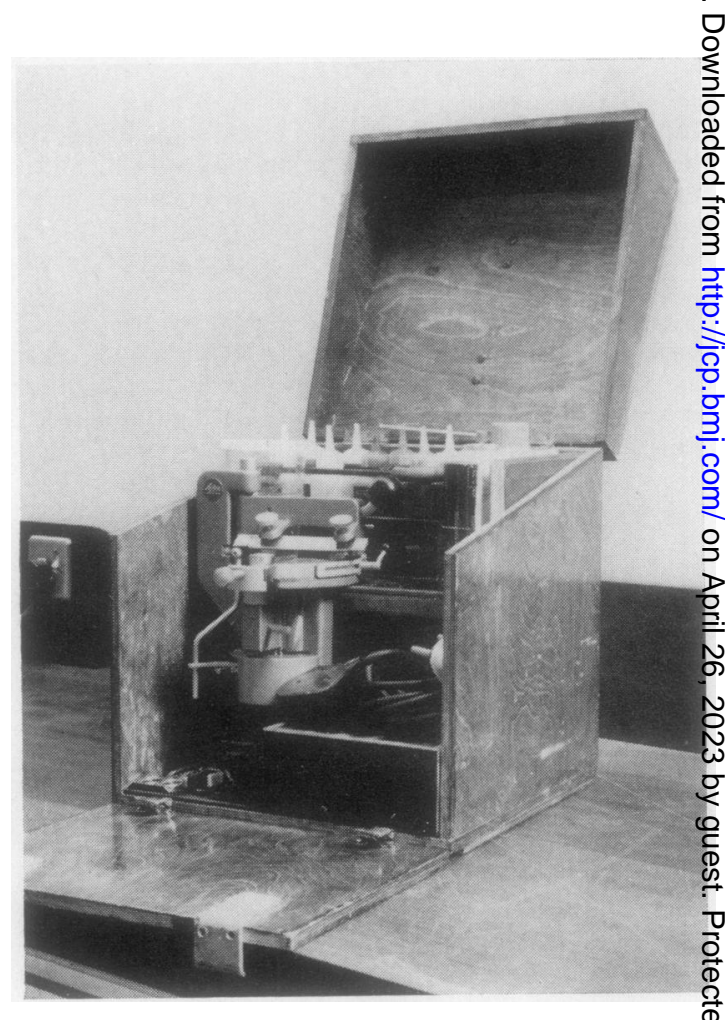

FIG. 1. Portable frozen section apparatus. Lids opened $\mathbb{D}$ show packed contents. 


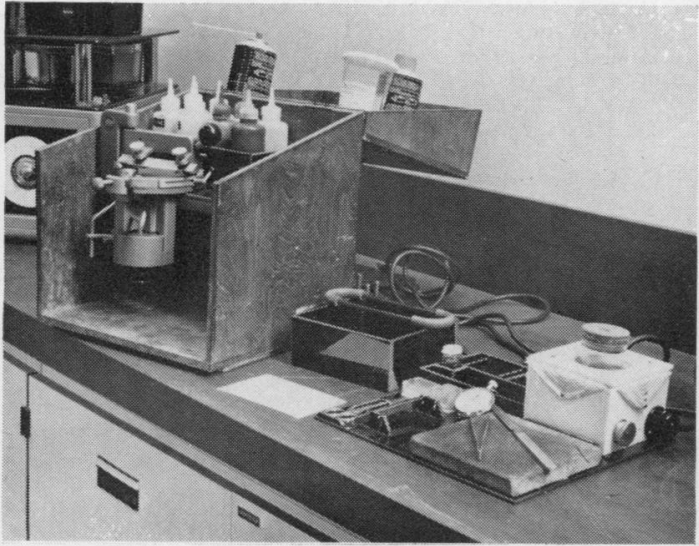

FIG. 2.

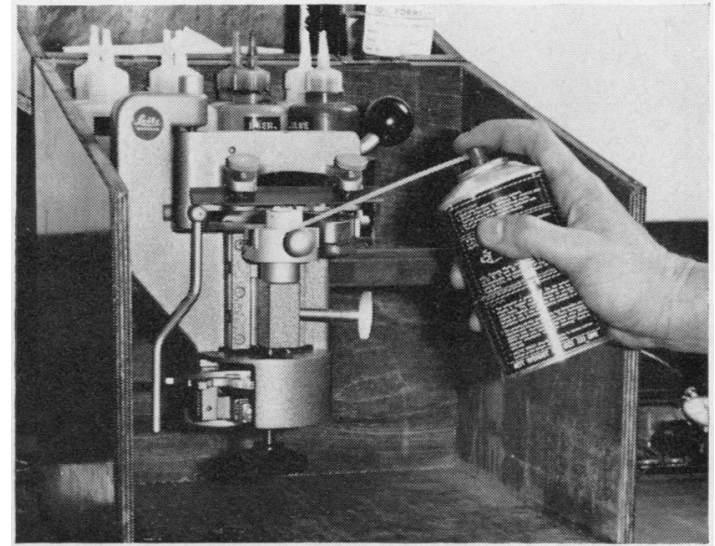

FIG. 3 .

FIG. 2. Portable frozen section apparatus unpacked ready for use.

FIG. 3. Portable frozen section apparatus in close-up to show application of dichloro-difluoromethane aerosol to microtome chuck.

rigid wooden box (size 12 in. $\times 12$ in. $\times 12$ in.) fitted with a drop front on detachable hinges for easy access. A Leitz small freezing microtome is bolted to a rigid shelf in the centre of the box. The microtome clamp has been modified by placing a sawn-off cryostat chuck in the simple clamp provided with the microtome, insulated from the clamp by thin sheets of perspex and packed with polyurethane foam. Thus modified the stage will remain frozen for up to seven or eight minutes without further freezing. All apparatus required for dissection, fixation, cutting, and staining is packed in containers constructed out of black perspex. As can be seen in the illustrations, when the apparatus is in use the tray from beneath the shelf is laid alongside the box and heating for rapid formalin fixation is provided by an electric heating mantle. If electricity is not available a simple spirit burner could be substituted.

\section{APPARATUS}

UPPER SHELF (1) Leitz small freezing Microtome (fixed);
(2) set of eight stains, dehydrants etc. in soft polythene containers; (3) two cans Arctic Spray; (4) formalin histology containers; (5) electric lead with universal plug.

LOWER DETACHABLE SHELF (1) Heating mantle; (2) slide tray; (3) cork diseccting board (6 in. square); (4) cover slips and mounting medium; (5) instruments (knife, scissors, forceps, and slide diamond); (6) water bath for floating sections; (7) staining rack; (8) blotting paper.

\section{METHOD}

Arctic Spray is introduced into and around the modified microtome stage and sprayed directly on the tissue in a series of 10 to 12 second bursts. Sectioning is then performed in the usual way.

\section{REFERENCE}

Thomas, G. (1965). Trans. Ass. industr. med. Offrs, 15, 105. 